\title{
Aplikasi Jaringan Syaraf Tiruan Untuk Clustering Polutan Kimia Penyebab Pencemaran Udara
}

\author{
Nur Yanti ${ }^{1)}$, Maria Ulfah ${ }^{2)}$ \\ 1) Teknik Elektronika, Politeknik Negeri Balikpapan \\ nur.yanti@poltekba.ac.id \\ ${ }^{2)}$ Teknik Elektronika, Politeknik Negeri Balikpapan \\ maria.ulfah@poltekba.ac.id
}

\begin{abstract}
The problem of air pollutionis a serious problem faced by big cities in Indonesia even in the world. Air pollution can come from a wide range, among others: motor vehicle fumes, factory smoke, industries waste, house hold waste, etc The current air pollution has reached alarm ing levels, as supported by the development of the industrial world, increasing human population, the greater the resulting environmental pollution. Decreasedair quality due to the content of chemical substances as pollutants have negative impacts on human life that is healthy environmental degradation, health problems, toserious environmental damage. Increasedair pollution as the negative impact caused by pollutants, pollutants required clustering based on the load of pollutants containing hazard ous chemical sare produced. Group ing pollutants by using Artificial Neural Network (ANN). Clustering chemical pollutants using artificial neural network method Learning Vector Quantization (LVQ produce 0.0011719 learning rate, with a target error 0001 epoch reached on the 10th. Clusteringis generated in the form of area in the city of Balikpapan as a regional cluster based chemical pollutants cause air pollution and the negative impact of these pollutants, as well as used as information for regional development policiesin particular, in order totake appropriate measuresto preventandcope with air pollution.
\end{abstract}

Keywords: Artificial Neural Networks, LVQ, Chemical Pollutants, Air Pollution.

\begin{abstract}
Abstrak
Masalah pencemaran udara merupakan masalah serius yang dihadapi oleh kota-kota besar di Indonesia bahkan di dunia. Pencemaran udara dapat bersumber dari berbagai macam, antara lain : asap kendaraan bermotor, asap pabrik, limbah indutri, limbah rumah tangga dan sebagainya. Pencemaran udara saat ini sudah mencapai tingkat mengkhawatirkan, karena didukung oleh perkembangan dunia industri, meningkatnya populasi manusia mengakibatkan semakin besar pula terjadinya pencemaran lingkungan. Menurunnya kualitas udara akibat kandungan zat-zat kimia sebagai polutan membawa dampak negatif bagi kehidupan manusia yaitu menurunnya kualitas lingkungan sehat, gangguan kesehatan, hingga kerusakan lingkungan yang serius. Meningkatnya pencemaran udara sebagai dampak negatif yang disebabkan oleh polutan, diperlukan clustering polutan berdasarkan beban polutan yang mengandung zat-zat kimia berbahaya yang dihasilkan. Pengelompokan polutan dengan menggunakan Jaringan Syaraf Tiruan (JST). Clustering polutan kimia menggunakan Jaringan Syaraf Tiruan dengan metode Learning Vector Quantization (LVQ) menghasilkan learning rate 0.0011719, dengan target error 0.001 tercapai pada epoch ke-10. Clustering yang dihasilkan berupa daerah di wilyah Kota Balikpapan sebagai daerah cluster berdasarkan polutan kimia penyebab pencemaran udara dan dampak negatif akibat polutan tersebut, serta digunakan sebagai informasi untuk kebijakan pembangunan daerah khususnya, agar mengambil langkah yang tepat dalam mencegah dan mengatasi pencemaran udara.
\end{abstract}

Kata Kunci : Jaringan Syaraf Tiruan, LVQ, Polutan Kimia, Pencemaran Udara. 


\section{Pendahuluan}

Menurut Undang-undang Pokok Pengelolaan Lingkungan Hidup No. 4 tahun 1982, pencemaran lingkungan atau polusi adalah masuknya atau dimasukkannya makhluk hidup, zat energi, dan atau komponen lain ke dalam lingkungan, atau berubahnya tatanan lingkungan oleh kegiatan manusia oleh proses alam sehingga kualitas lingkungan turun sampai ke tingkat tertentu yang menyebabkan lingkungan menjadi tidak dapat berfungsi lagi sesuai dengan peruntukannya.

Yang dikatakan sebagai polutan adalah suatu zat atau bahan yang kadarnya melebihi ambang batas serta berada pada waktu dan tempat yang tidak tepat, sehingga merupakan bahan pencemar lingkungan, misalnya: bahan kimia, debu, panas dan suara.

Pencemaran udara adalah peristiwa masuknya, atau tercampurnya, polutan (unsurunsur berbahaya) ke dalam lapisan udara (atmosfer) yang dapat mengakibatkan menurunnya kualitas udara (lingkungan). Umumnya, polutan yang mencemari udara berupa gas dan asap. Gas dan asap tersebut berasal dari hasil proses pembakaran bahan bakar yang tidak sempurna, yang dihasilkan oleh mesin-mesin pabrik, pembangkit listrik dan kendaraan bermotor. Selain itu, gas dan asap tersebut merupakan hasil oksidasi dari berbagai unsur penyusun bahan bakar, yaitu: $\mathrm{CO} 2 \quad$ (karbondioksida), $\mathrm{CO}$ (karbonmonoksida), SOx (belerang oksida) dan NOx (nitrogen oksida).

\subsection{Tujuan}

Peningkatan pencemaran udara serta dampak negatif yang disebabkan oleh polutan, diperlukan clustering polutan berdasarkan beban polutan yang mengandung zat-zat kimia berbahaya yang dihasilkan dari berbagai aktivitas pada faktor internal dan eksternal penyebab pencemaran udara. Hasil dari clustering polutan kimia ini dapat digunakan sebagai informasi untuk membantu pemerintah daerah khususnya dalam mengambil kebijakan dan menentukan langkah yang tepat dalam mencegah dan mengatasi pencemaran udara. Clustering polutan berdasarkan beban polutan kimia dapat dilakukan dengan menggunakan Jaringan Syaraf Tiruan (JST) dengan metode Learning Vector Quantization ( $L V Q)$.

Jaringan Syaraf Tiruan merupakan suatu jaringan yang mempunyai kemampuan untuk memetakan pola masukan melalui model pembelajaran pengawasan (supervised learning) dan pembelajaran tanpa pengawasan (unsupervised learning). Pemetaan yang dihasilkan akan menunjukkan hubungan keterkaitan antara pola-pola masukan tersebut dalam suatu representasi yang lebih ringkas dan akurat dari data aslinya dengan mempertahankan hubungan topologinya.

Jaringan syaraf tiruan merupakan generalisasi model matematis dengan beberapa asumsi berikut:

1. Pemrosesan informasi terjadi pada neuron.

2. Sinyal dikirimkan di antara neuron-neuron melalui penghubung dendrit dan akson.

3. Penghubung antar elemen memiliki bobot yang akan menambah atau mengurangi sinyal.

4. Untuk menentukan output, setiap neuron memiliki fungsi aktivasi yang dikenakan pada jumlah semuainputnya. Besar output akan dibandingkan dengan nilai threshold tertentu.

Berdasarkan model matematis tersebut, baik tidaknya suatu model JST ditentukan oleh hal-hal berikut:

1. Arsitektur jaringan, yaitu sebuah arsitektur yang menentukan pola antar neuron.

2. Metode pembelajaran (learning method), yaitu metode yang digunakan untuk menentukan dan mengubah bobot.

3. Fungsi aktivasi.

\subsection{Arsitektur Jaringan Syaraf Tiruan}

Hubungan antar neuron dalam jaringan syaraf mengikuti pola tertentu tergantung pada arsitektur jaringan syarafnya. Pada dasarnya ada 3 macam arsitektur jaringan syaraf, yaitu :

a. Jaringan syaraf dengan lapisan tunggal (single layer net). 
Jaringan dengan lapisan tunggal hanya memiliki satu lapisan dengan bobot-bobot terhubung. Jaringan ini hanya menerima input kemudian secara langsung akan mengolahnya menjadi output tanpa harus melalui lapisan tersembunyi. Dengan kata lain, ciri-ciri dari arsitektur jaringan syaraf dengan lapisan tunggal adalah hanya terdiri dari satu lapisan input dan satu lapisan output.

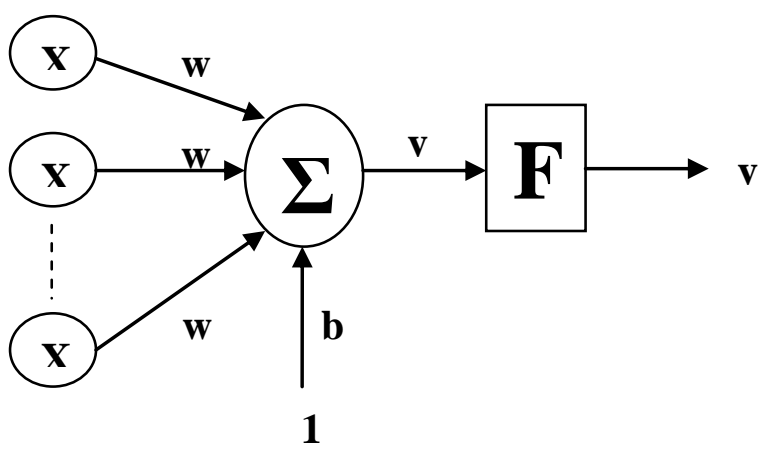

Gambar.1 Jaringan Syaraf Sederhana dengan Bias

b. Jaringan syaraf dengan banyak lapisan (multilayer net)

Jaringan dengan banyak lapisan memiliki satu atau lebih lapisan yang terletak diantara lapisan input dan laisan output (memiliki satu atau lebih lapisan tersembunyi). Umumnya, ada lapisan bobot-bobot yang terletak antara 2 lapisan yang bersebelahan. Jaringan dengan banyak lapisan ini dapat menyelesaikan permasalahan yang lebih sulit daripada lapisan dengan lapisan tunggal, tentu saja dengan pembelajaran yang lebih rumit

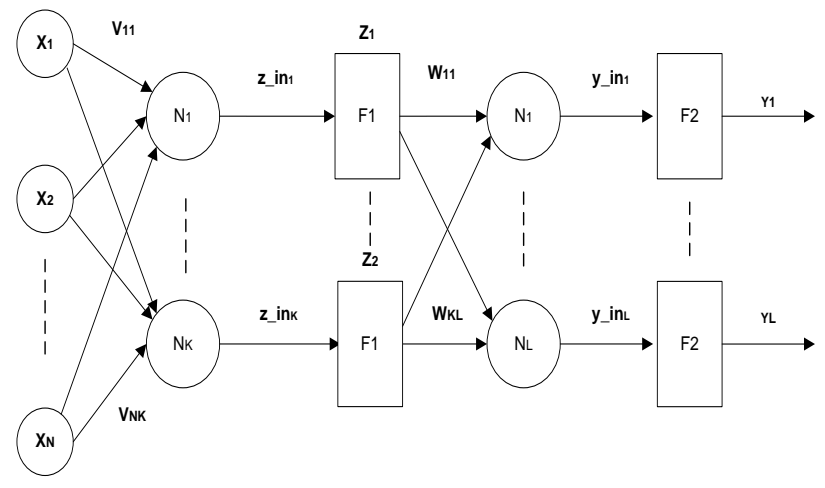

Gambar.2.Arsitektur Jaringan Syaraf Tiruan dengan Banyak Lapisan

Hanya ada 1 lapisan tersembunyi pada arsitektur jaringan pada gambar.2 tersebut, $\mathrm{v}_{\mathrm{ij}}$ adalah bobot-bobot yang menghubungkan antara neuron-neuron pada lapisan input dengan lapisan tersembunyi. Sedangkan $\mathrm{w}_{\mathrm{jk}}$ adalah bobot-bobot yang menghubungkan antara neuron-neuron pada lapisan tersembunyi dengan lapisan output. $Z_{-}$in $_{j}$ adalah hasil pengolahan data pada lapisan tersembunyi, dengan fungsi aktivasi F1 untuk menghasilkan $\mathrm{Z}_{\mathrm{j}}(\mathrm{j}=1, \ldots \mathrm{K})$;

$\mathrm{z} \_\mathrm{in}_{\mathrm{j}}=\sum_{i=1}^{N} x_{i} v_{i j}$

[Pers.1]

$\mathrm{z}_{\mathrm{j}}=\mathrm{F} 1\left(\mathrm{z} \_\mathrm{in} \mathrm{n}_{\mathrm{j}}\right)$

[Pers.2]

Sedangkan y_in ${ }_{\mathrm{k}}$ adalah hasil pengolahan data pada lapisan output, dengan fungsi aktivasi F2 untuk menghasilkan output jaringan $\mathrm{y}_{\mathrm{k}}$ $(\mathrm{k}=1, \ldots, \mathrm{L})$.

$\mathrm{y} \_$in
$\mathrm{y}_{\mathrm{k}}=\mathrm{F} 2\left(\mathrm{y} \_\sum_{j=1}^{N} z_{\mathrm{k}}\right)$

[Pers.3]

[Pers.4]

\section{c. Jaringan syaraf dengan lapisan kompetitif} (competitive layer net)

Arsitektur ini memiliki bentuk yang berbeda, dimana antar neuron dapat saling dihubungkan.

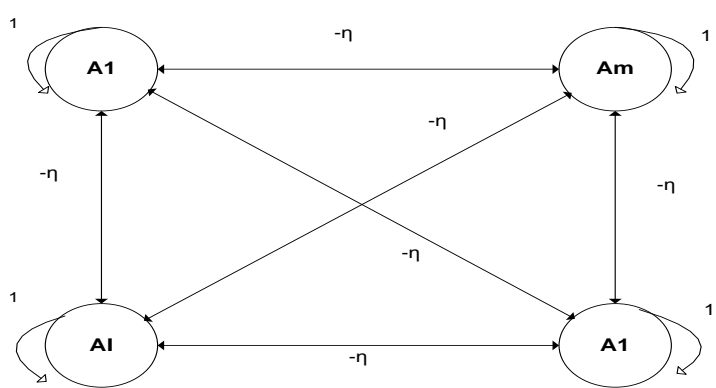

Gambar.3. Jaringan Syaraf Tiruan dengan Lapisan Kompetitif 


\subsection{Metode Pelatihan Jaringan Syaraf Tiruan (Neural Network)}

Prosedur yang digunakan Jaringan Syaraf Tiruan dalam mencari pengaturan bobot yang tepat mengacu pada paradigma belajarnya (learning paradigm). Paradigma belajar inilah yang dikenal sebagai algoritma belajar dalamJaringan Syaraf Tiruan. Berdasarkan strategi pelatihan, paradigma belajar Jaringan Syaraf Tiruan dapat diklasifikasikan menjadi dua paradigma:

1. Pembelajaran Terawasi (Supervised Learning)

Metode pembelajaran pada jaringan syaraf disebut terawasi jika output yang diharapkan telah diketahui sebelumnya.

2. Pembelajaran Tak Terawasi (Unsupervised Learning)

Pada metode pembelajaran yang tak terawasi tidak memerlukan target output. Pada metode ini, tidak dapat ditentukan hasil yang seperti apakah yang diharapkan selama proses pembelajaran.

\subsection{Learning Vector Quantization (LVQ)}

Learning Vector Quantization (LVQ) merupakan suatu metode untuk melakukan pelatihan terhadap lapisan-lapisan kompetitif terawasi. Lapisan kompetitif LVQ akan belajar secara otomatis untuk melakukan klasifikasi terhadap vektor input (data input) yang diberikan. Apabila beberapa vektor input memiliki jarak yang sangat berdekatan, maka vektor-vektor input tersebut akan dikelompokkan dalam kelas yang sama. [Kusumadewi, 2004].

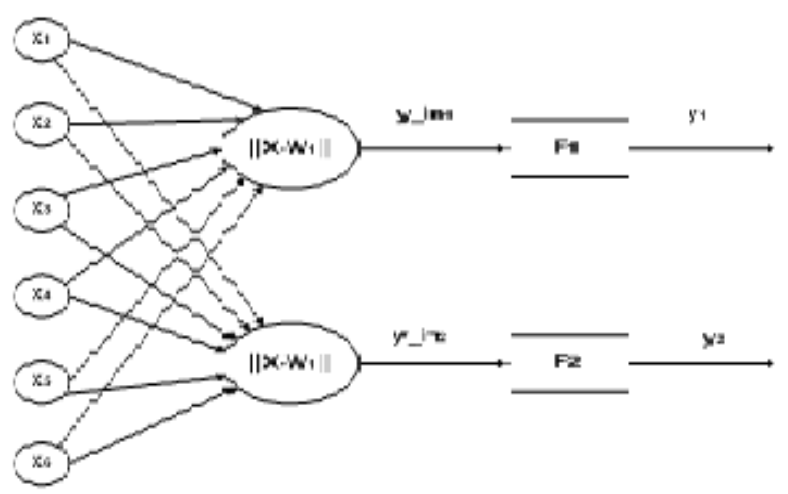

Gambar.4. Arsitektur Jaringan LVQ

\subsection{Algoritma Learning Vector Quantization (LVQ)}

Algoritma pengelompokan pola pembelajaran LVQ adalah sebagai berikut:

Algoritma Pembelajaran LVQ

a. Tetapkan :

- Bobot awal variabel input ke-j menuju kelas (cluster) ke-i : wij;

- Parameter learning rate ( $\alpha$ );

- Pengurangan learning rate;

- Target error

b. Masukkan:

- Data input : Xij

- Target berupa kelas : Tk

c. Tetapkan kondisi awal : epoch $=0$;

d. Kerjakan jika : $(\alpha \geq \operatorname{Min} \alpha)$

- epoch $=$ epoch +1 ;

- kerjakan untuk $\mathrm{i}=1$ sampai $n$

- Tentukan J sedemikian hingga $\|\mathrm{Xi}-\mathrm{Wj}\|$ minimum;

- Perbaiki Wj dengan ketentuan:

$\rightarrow$ Jika $\mathrm{T}=\mathrm{Cj}$ maka : $\mathrm{Wj}=\mathrm{Wj}+\alpha(\mathrm{Xi}-\mathrm{Wj})$ $\rightarrow$ Jika $\mathrm{T} \neq \mathrm{Cj}$ maka :

- Kurangi nilai $\alpha$.

Algoritma Pengujian LVQ

a. Masukkan data yang akan diuji : Xij

b. Kerjakan untuk $i=1$ sampai $n$

- Tentukan J sedemikian hingga $\|\mathrm{Xi}-\mathrm{Wj}\|$ minimum

- J adalah kelas untuk Xi

\section{Metoda Penelitian}

Pada penelitian ini dilakukan clustering polutan kimia sebagai penyebab pencemaran udara di Kota Balikpapan dengan menggunakan Jaringan Syaraf Tiruan. Metode penelitian yang dilakukan yaitu kombinasi metode penelitian kualitatif dan kuantitatif. Adapun tipe penelitian kombinasi yang digunakan adalah Sequential Exploratory Design, yaitu pada tahap awal penelitian menggunakan metode kualitatif dan tahap berikutnya menggunakan metode kuantitatif. 


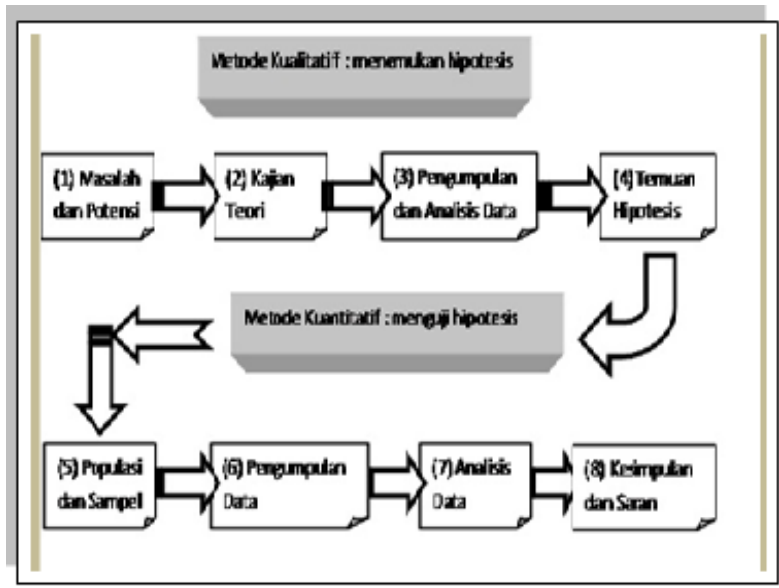

Gambar.5. Alur MetodologiPenelitian

\section{Hasil Dan Pembahasan}

Clustering pencemaran udara yang dilakukan terhadap kualitas udara ambien. Untuk mengetahui kualitas udara perkotaan di kota Balikpapan, dilakukan pengukuran pada beberapa titik lokasi yang srtategis dengan berbagai peruntukkan dan pengukurannya dilakukan secara sesaat maupun kontinyu.

Pengukuran kualitas udara terakhir dilakukan pada tahun 2014, dilakukan secara laboratorium pada 6 (enam) lokasi terutama lokasi dengan kepadatan lalu lintas tinggi dan mengacu pada tempat yang sama dari yahuntahun sebelumnya yaitu pada:

1. Simpang Balikpapan Plaza, Jl. Jend. Sudirman, Kelurahan Klandasan Ilir, merupakan pengukuran pada jalan raya (5m dari tepi jalan).

2. Terminal Damai, Kelurahan Damai, merupakan daerah perdagangan dan jasa.

3. Pelabuhan Laut Semayang, Kelurahan Prapatan, merupakan daerah jasa dalam hal ini pelayananjasa transportasi laut.

4. Simpang Gunung Malang, Kelurahan Gunung Sari, merupakan daerah perdagangan dan jasa.

5. Kampung Baru Ujung, Kelurahan Baru Ulu, merupakan daerah perdagangan, jasa dan pemukiman.

6. Bundaran Rapak, Kelurahan Rapak, merupakan daerah perdagangan dan jasa.

Adapun hasil pengukuran senyawa kimia penyebab pencemaran udara di Kota
Balikpapan pada tahun 2014 diuraikan untuk tiap-tiap parameter sebagai berikut:

Tabel.1 Udara Ambien

\begin{tabular}{|l|c|c|c|}
\hline \multirow{2}{*}{$\begin{array}{l}\text { LOKASI } \\
\text { PEMANTAUAN }\end{array}$} & \multicolumn{3}{|c|}{ PARAMETER } \\
\cline { 2 - 4 } & $\begin{array}{c}\mathrm{S} 02 \\
\text { (ug/Nm3) }\end{array}$ & $\begin{array}{c}\text { C0 } \\
\text { (ug/Nm3) }\end{array}$ & N02 (ug/Nm3) \\
\hline Simpang Balikpapan Plaza & 33.17 & 5.579 & 17.88 \\
\hline Area Terminal Damai & 36.42 & 5.636 & 17.79 \\
\hline Area Pelabuhan Laut & 30.46 & 5.293 & 17.95 \\
\hline Area Simpang Gn. Malang & 30.71 & 5.304 & 17.80 \\
\hline Area Kampung Baru Ujung & 33.30 & 5.613 & 17.73 \\
\hline Area Bundaran Rapak & 30.46 & 5.293 & 17.95 \\
\hline Baku Mutu Udara & 365 & 10000 & 150 \\
\hline
\end{tabular}

Sumber : 1. Badan Lingkungan Hidup Kota Balikpapan

2. Lampiran PPRI No. 41 Tahun 1999

\subsection{Analisis Learning Vector Quantization (LVQ)}

Algoritma pembelajaran LVQ diterapkan dalam pengelompokkan data (clustering) senyawa kimia (polutan kimia) sebagai penyebab pencemaran udara di Kota Balikpapan. Dalam penelitian ini, untuk mengelompokkan data menjadi cluster-cluster, langkah awal adalah membangun topologi jaringan syaraf tiruan dengan menentukan bobot awal untuk variabel input, parameter learning rate, pengurangan learning rate, target error dan maksimal epoch. Setelah penetuan variabel-variabel tersebut, dilakukan pelatihan serta pengujian data, sehingga dihasilkan cluster-cluster data yang merupakan hasil pembelajaran algoritma LVQ.

\subsection{Transformasi Data}

Data ditransformasikan ke interval $[0,1]$. Tapi akan lebih baik jika ditransformasikan ke interval yang lebih kecil, misal pada interval $[0.1,0.9]$. Transformasi linear yang dipakai untuk mentransformasikan data ke interval $[0.1,0.9]$ adalah: 


$$
x^{\prime}=\frac{0.8(x-a)}{b-a}+0.1
$$

Jika a adalah data minimum dan $b$ adalah data maksimum, x merupakan nilai aktual.

\subsection{Clustering Data}

Dalam clustering polutan kimia sebagai penyebab pencemaran udara, data dibagi menjadi 3 (tiga) cluster berdasarkan dampak negatif yang ditimbulkan oleh polutan kimia tersebut. Pengelompokan (cluster) sebagai berikut:

1. Cluster-1 : Daerah dengan polutan kimia yang menyebabkan gangguan kesehatan manusia dan berdampak negatif terhadap pertumbuhan tanaman pangan.

2. Cluster-2 : Daerah dengan polutan kimia yang mengakibatkan pemanasan global.

3. Cluster-3 : Daerah dengan polutan kimia yang dapat mengakibatkan korosi terhadap alat dan mesin logam.

Topologi jaringan syaraf tiruan dengan algoritma pembelajaran Learning Vector Quantization (LVQ) sebagai berikut:

- Jumlah data $=6$

- Jumlah variabel input $=3$

- Jumlah cluster yang diinginkan $=3$

- $\quad$ Learning rate $=0.6$

- Pengurangan learning rate $=0.5$

- Target error $=0.001$

- Maksimum epoch ditetapkan sebesar 100

- Bobot awal yang digunakan:

$$
w=\left[\begin{array}{lll}
0.5 & 0.5 & 0.5 \\
0.5 & 0.5 & 0.5 \\
0.5 & 0.5 & 0.5
\end{array}\right]
$$

Proses training terus dilakukan hingga tercapai target error atau maksimum epoch. Pada proses training ini, target error tercapai pada epoch ke-10 yaitu dengan learning rate sebesar 0.0011719 dan diperoleh bobot akhir sebagai berikut :
Bobot akhir :

$$
w=\left[\begin{array}{lll}
0.67 & 0.66 & 0.14 \\
0.18 & 0.18 & 0.37 \\
0.14 & 0.12 & 0.88
\end{array}\right]
$$

Tabel .2 Hasil pengujian data pelatihan

\begin{tabular}{|c|c|c|c|c|c|}
\hline \multirow{2}{*}{$\begin{array}{c}\text { Data } \\
\text { ke- } \\
\left(\mathbf{x}_{\mathbf{n}}\right)\end{array}$} & \multicolumn{3}{|c|}{$\begin{array}{c}\text { Jarak vektor - } \\
\text { bobot }\end{array}$} & \multirow{2}{*}{$\begin{array}{c}\text { Kelas } \\
\text { (Cluster) }\end{array}$} & Target \\
\hline 1 & 0.56 & 0.71 & 0.76 & $1^{*}$ & 2 \\
\hline 2 & 0.37 & 1.02 & 1.23 & 1 & 1 \\
\hline 3 & 1.10 & 0.54 & 0.05 & 3 & 3 \\
\hline 4 & 0.79 & 0.073 & 0.53 & 2 & 2 \\
\hline 5 & 0.27 & 0.78 & 1.12 & 1 & 1 \\
\hline 6 & 1.10 & 0.54 & 0.05 & 3 & 3 \\
\hline
\end{tabular}

Dari hasil pengujian data pelatihan, data pertama tidak sesuai dengan target, yang seharusnya masuk dalam kelas ke-2 (cluster2), namun dari hasil pengujian data pertama masuk dalam kelas- 1 (cluster-1).

\section{Kesimpulan Dan Saran}

Pembelajaran LVQ mampu menghasilkan cluster yang sama dengan target data yang diinginkan. Proses training yang dilakukan dengan algoritma LVQ dapat tercapai pada waktu relatif singkat dengan target error sebesar 0.001 pada epoch ke-10, menghasilkan learning rate 0.0011719 . Kinerja algoritma pembelajaran LVQ sangat baik digunakan untuk tipe data input dengan jumlah variabel input yang tidak terlalu banyak, namun tetap dapat melakukan proses training dengan jumlah data yang banyak.

\section{Ucapan Terima Kasih}

Ucapan terima kasih kepada P3M Politeknik Negeri Balikpapan yang telah memberikan pendanaan dalam pelaksanaan penelitian dan Badan Lingkungan Hidup Kota Balikpapan yang telah membantu sebagai sumber data dan informasi sehingga penelitian ini berjalan baik dan lancar. 


\section{Daftar Pustaka}

[1] Drs. Siang Jek Jong, M.Sc. 2009. Jaringan Syaraf Tiruan \& Pemrogramannya Menggunakan Matlab. Andi Yogyakarta.

[2] Fausett, L. 1994. Fundamentals of Neurals Network, Architecture, Algorithms, and Applications, Prentice Hall.

[3] Haykin, S. 1994. Neural Networks, a Comprehensive Foundation, Prentice Hall.
[4] Kosko, B. 1992. Neural Networks and Fuzzy Systems : A Dynamic Systems Approach to Machine Intelligence, Prentice Hall.

[5] LiMin Fu. 1994. Neural Networks in Computer Intelligence. McGraw-Hill, Inc.

[6] Kusumadewi, D. 2003. Artificial Intelligence, Teknik dan Aplikasi. Graha Ilmu. Yogyakarta.

[7] Kusumadewi, D. 2004. Membangun Jaringan Syaraf Tiruan. Graha Ilmu. Yogyakarta 